\section{Práticas discursivas de colonialidade no aplicativo Grindr: a masculinidade homoerótica patologizada}

Discursive practices of coloniality on Grindr app: pathologized homoerotic masculinity

Rusanil dos Santos MOREIRA JÚNIOR (UFAL) rusanil.junior@fale.ufal.br

Sérgio IFA (UFAL) sergio@fale.ufal.br

Recebido em: 06 de nov. de 2020. Aceito em: 07 de maio de 2021.
MOREIRA JÚNIOR, Rusanil dos Santos; IFA, Sérgio. Práticas discursivas de colonialidade no aplicativo Grindr: a masculinidade homoerótica patologizada. Entrepalavras, Fortaleza, v. 11, n. 3, e2149, p. 255-276, set.dez./2021. DOI: 10.22168/2237-632132149 .

Resumo: Sob a perspectiva da Linguística Aplicada, este artigo objetiva analisar as linguagens e os discursos construídos e (re)produzidos sobre masculinidade homoerótica no Grindr, um aplicativo social para gays. Entende-se que as práticas discursivas são motivadas por escolhas ideológicas que provocam e perpetuam diferentes efeitos no mundo social: normalização e controle de certas visões sobre outras. Nessa perspectiva, este trabalho se apoia nos estudos sobre colonialidade do poder, nos estudos queer e nos estudos sobre as masculinidades. Para as interpretações, foram consideradas as informações relacionadas ao layout do Grindr, as categorias relacionadas ao perfil de usuário e 167 respostas de perfis de usuários. Os resultados evidenciam uma masculinidade homoerótica patologizada e (re)produzida, sob a égide de uma masculinidade hegemônica, a partir de discursos coloniais socializados em um regime de terrorismo cultural.

Palavras-chave:Discursos. Colonialidade. Masculinidade. Homossexualidade.

Aplicativo Grindr. 
V. 11 (3) 255-276

Abstract: From the perspective of Applied Linguistics, this article aims to analyze homoerotic masculinity languages and discourses built and (re)produced on Grindr, a social networking app for gay people. Discursive practices are understood to be motivated by ideological choices that provoke and perpetuate different effects on the social world: normalization and control of certain views over others. So, this investigation is based on studies on coloniality of power, queer studies and studies on masculinities. For the interpretations, we considered the information related to the Grindr layout, the categories related to user profile and 167 user profiles. The results show a pathologized homoerotic masculinity and (re)produced, under the aegis of a hegemonic masculinity, based on socialized colonial discourses in a regime of cultural terrorism.

Keywords: Discourses. Coloniality. Masculinity. Homosexuality. Grindr app.

\section{Introdução}

Não deve ser estranha ao leitor a célebre frase da filósofa francesa Simone de Beauvoir "Não se nasce mulher, torna-se mulher", um dos principais lemas do movimento feminista no final do século passado. Utilizando-se da mesma ideia, Elisabeth Badinter, também filósofa francesa feminista, ressignifica-a de forma análoga: "O homem não nasce homem, ele se torna homem" (BADINTER, 1993, p. 29). Ambas as afirmações nos propõem uma reflexão sobre a construção da feminilidade e masculinidade, as quais não são determinadas pela biologia, mas pelo seio social, no qual a existência parece preceder a essência. Essa essência, por sua vez, é culturalmente nutrida pelos padrões patriarcais, de forma desajustada, em função das relações coloniais de poder que constroem e perpetuam verdades arbitrárias - impostas em cada momento histórico - sobre como ser homens e mulheres, um modelo cultural que está sob constante vigilância e coerção sociais para se perpetuar e produzir os efeitos homogeneizadores que deseja. Esses efeitos influenciam diretamente no imaginário social das pessoas, os quais se inscrevem em discursos que atravessam o tempo e a história, dilacerando mentes e corpos. Nessa perspectiva, servindonos também da máxima de Beauvoir: uma verdade não nasce verdade, torna-se verdade - embora sempre contingente (MOITA LOPES, 2009).

Àluz dessa compreensão, não há como pensar a masculinidadee suas projeções sociais sem relacioná-la à feminilidade. Historicamente, a primeira foi insistentemente determinada pelo afastamento dos atributos do que a segunda é ou vinha a ser entendida, e é no corpo que o poder se provê e materializa o que se espera de homens e mulheres desde que nascemos. Dessa forma, entendemos que a masculinidade assim como a feminilidade são construções sociais em que um modelo 
dominante se sobressai como referência de normalidade, o qual conduz os comportamentos de toda uma comunidade ou sociedade. Ao pensar na construção de homens e mulheres como seres sociais, houve, e ainda há, uma relação vertical em que o gênero mulher esteve histórica e continuamente subordinado ao gênero homem, definindo os papéis sociais de cada um deles. Não é de forma imotivada o entendimento de que o signo" "homem" pode, em determinados contextos, ser interpretado como "ser humano", independente do gênero desse ser ou de como ele se determina, o que nos remete a uma precarização da existência do gênero feminino nas relações hegemônicas de poder.

Apesar do privilégio masculino na construção da história da humanidade, ressaltamos que nem todas as masculinidades possuem a mesma legitimidade social. Existiram e ainda existem determinadas características físicas e até psíquicas que conferem à masculinidade dominante o caráter de normalidade e, consequentemente, prestígio e respeito sociais. O mesmo sistema que fortalece a masculinidade também a regula por meio de critérios como questões de raça, sexualidade, classe social e condições financeiras. Compreendemos, portanto, que existem "hierarquias de poder entre distintos grupos de homens, e não apenas o poder patriarcal institucionalizado, dos homens em relação às mulheres" (JANUÁRIO, 2016, p. 98). É no plano dessas posições hierárquicas entre as masculinidades que este estudo se envereda.

Este artigo propõe apresentar análises de possíveis leituras das linguagens e discursos construídos e (re)produzidos sobre a masculinidade homoerótica em um popular aplicativo voltado para a sociabilidade gay, o Grindr. A Linguística Aplicada, como ciência e prática interrogadoras, problematizadoras e atravessadas por valores, na qual este trabalho se insere, compreende que as práticas discursivas não são neutras, são motivadas por escolhas ideológicas - intencionais ou não - que provocam e perpetuam diferentes efeitos no mundo social (MOITA LOPES, 2006; FABRÍCIO, 2006), e são os efeitos de normalização e controle que estão no cerne das interpretações.

Nessa perspectiva, esta pesquisa é resultante de percepções e estranhamentos entendidos como práticas de colonialidade, de combate ao comportamento socialmente categorizado como homoerótico nas interações sucedidas em um aplicativo criado para homens que buscam se relacionar com pessoas do mesmo sexo, o que implicou no questionamento ético dessas práticas. Entendemos, portanto, que a

\footnotetext{
${ }^{1}$ Entendido na perspectiva do Círculo de Bakhtin.
} 
V. $11(3)$ $255-276$ set-dez 2021

língua é ação, atividade, uma cadeia significante situada historicamente que reflete e refrata a realidade (VOLÓCHINOV, 2018) e, por isso, está indissocialmente vinculada ao comportamento social dos sujeitos, aos nossos modelos de recusa e aceitação. Portanto, seria ficção pensar que, ao produzir linguagens/discursos, somos produtores únicos, isolados e assépticos, uma vez que os discursos atravessam o tempo e a história e agem sobre todas as vidas indiscriminada e impiedosamente, regulando-as.

Para tanto, a seguir, o presente texto faz ponderações teóricas a respeito das teorias fundantes deste trabalho, a saber: a colonialidade do poder; a abjeção, pautada nos estudos queer, e as masculinidades. Na sequência, discorremos o processo de constituição dos dados; seguidamente, desenvolvemos as nossas interpretações à luz das teorias supracitadas e, por fim, apresentamos as considerações finais do estudo.

\section{Colonialidade do poder, abjeção e masculinidades}

"Colonialidade do poder" é um conceito cunhado pelo sociólogo peruano Aníbal Quijano, em 1989, que não deve ser confundido com "colonialismo", embora haja uma correlação. Conforme MaldonadoTorres (2007, p. 130), a colonialidade "refere-se à interrelação entre as formas modernas de exploração e dominação" "2 que não desapareceu com o definhamento do colonialismo, o qual denota um sistema econômico e político de controle e comando de terras estrangeiras por parte de um Estado. Isso significa dizer que o colonialismo chegou ao seu fim, mas os seus efeitos perduram, os quais estamos denominando de colonialidade, por meio da classificação social da população de todo o mundo, com a ideia de raça (QUIJANO, 2000). O objetivo da colonialidade é legitimar e perpetuar as relações assimétricas e abissais de controle e poder, operando "em cada um dos planos, âmbitos e dimensões, materiais e subjetivos, da existência humana" (MOTA NETO, 2016, p. 75).

Tal como esclarece Ballestrin (2013), a colonialidade do poder se funda em duas questões basilares: não apenas denuncia as formas coloniais de dominação após o extermínio das colônias nas nossas formas de entender o mundo e nos relacionarmos nele, mas, principalmente, contemporiza a continuidade desses processos hegemônicos que pareciam ter sido superados ou resolvidos pela modernidade. A colonialidade, como uma matriz colonial de poder

${ }^{2}$ No original: "se refiere a la interrelación entre formas modernas de explotación y dominación". 
(MIGNOLO, 2017), ideia desenvolvida por Quijano, sustenta-se como resultado do colonialismo moderno (MALDONADO-TORRES, 2007), erguida sob uma coluna fraturada que resiste em sanar-se. O machismo, a misoginia, o sexismo, o racismo, a homofobia são, decerto, algumas das chagas residuais dessas relações coloniais que se reproduzem de forma descomedida.

A colonialidade se mantém nutrida nos livros didáticos, nas relações familiares, nas bases de religiões hegemônicas, nas representações políticas, no imaginário social sobre o outro e acerca do que acreditamos sobre nós mesmos, nas nossas aspirações, na pesquisa acadêmica, no senso comum e em tantos outros aspectos das nossas experiências vividas, ou seja, "respiramos a colonialidade na modernidade cotidianamente")3 (MALDONADO-TORRES, 2007, p. 131) e, muitas vezes, ela não é percebida ou consciente. É válido salientar que a modernidade não está sendo compreendida aqui como o momento histórico da concepção de sucessivas inovações tecnológicas nas mais variadas áreas de produção humana, mas como um mito (DUSSEL, 1994) que, com a promessa de resolver os problemas sociais, acabaram por robustecê-los, orientados por padrões hierárquicos globais a partir do momento histórico em que

às Américas chegou o homem heterossexual/branco/patriarcal/ cristão/militar/capitalista/europeu, com as suas várias hierarquias globais enredadas e coexistentes no espaço e no tempo (GROSFOGUEL, 2008, p. 122).

Como consequência disso, surgem e fortalecem-se as hierarquias nas relações de poder, os padrões patriarcais, a naturalização de pensamentos ortodoxos, a invisibilidade de grupos não hegemônicos, chegando até à desumanização destes, normalizando os abismos sociais, econômicos, culturais e históricos em que se construiu a modernidade. Resistentemente a essas questões, os estudos queer - cuja luta política é a crítica a esses regimes de normalização, a qual não se circunscreve à sexualidade, senão a todas as diferenças que são notabilizadas para descartar o outro - põem em pauta um conceito muito caro a este trabalho: a abjeção. "A abjeção, em termos sociais, constitui a experiência de ser temido e recusado com repugnância, pois sua própria existência ameaça uma visão homogênea e estável do que é a comunidade" (MISKOLCI, 2017, p. 24). Na direção que caminha o autor, a abjeção relega ao outro

${ }^{3}$ No original: "respiramos la colonialidad en la modernidad cotidianamente". 
V. 11 (3) 255-276 set-dez 2021 um espaço inferior de existência, um espaço de negação - um "nãoespaço", como preferimos chamar - que ameaça o gerenciamento da ordem social. Esse não-espaço foi classificado pela coletividade como impuro, incorreto ou anormal (MISKOLCI, 2017), uma vez que "a colonialidade capitalista moderna, eurocêntrica e patriarcal consiste em identificar diferença com desigualdade, ao mesmo tempo que se arroga o privilégio de determinar quem é igual e quem é diferente" (SANTOS, 2018, p. 65).

Em vista disso, a masculinidade homoerótica é diariamente nutrida pela abjeção e estranhamentos que buscam perpetuar essas noções. Por isso, não é estranho encontrar homossexuais como agentes heteronormativos nessa empreitada, cujo efeito pode ser um produto do empreendimento colonial, alimentada nos diversos meios sociais que perfilam o que é ser um homem masculino. Essa orientação os induz a adotar comportamentos socialmente caracterizados como heterossexuais na tentativa de desintegrar-se do não-espaço que lhes já é imputado por essa condição sexual, posto que a abjeção ao homem homoerótico possui um perfil que não se aplica a todos os homossexuais. A raça, a classe social e, principalmente, os seus comportamentos e suas preferências sociais ${ }^{4}$ vão determinar os modelos de aceitação social. Quanto mais próximos do perfil heterossexual, mais tolerado o gay vai ser socialmente, "não por acaso, violências atualmente chamadas de homofobia não se dirigem a todos/as os/as homossexuais, mas, antes, mais frequentemente a quem não segue esse padrão" (MISKOLCI, 2017, p. 15).

A abjeção perverte o desejo homoerótico ao estágio de haver um esforço social por aniquilá-lo. A sua força é tão impetuosa - e colonial - que leva a uma demanda violenta de que gays e lésbicas sejam "discretos" para que não perturbem a paisagem social e existam com o mínimo de segurança. Essa é uma questão que não só preocupa os homossexuais senão a todos aqueles que buscam uma sociedade mais justa, por isso

não são apenas homossexuais que se sentem em contradição com as normas, afinal, há muito mais pessoas em desacordo com as convenções culturais, com as obrigações que nos são impostas em termos de comportamento (MISKOLCI, 2017, p. 26).

${ }_{4}^{4}$ Gostos musicais, vestuário, ambientes que frequenta, entre outras. 
Conforme foi desenvolvido até aqui, não é possível falar de masculinidade, no singular. Existem, portanto, masculinidade(s), no plural. As noções de ser homem, que se estende ao ser mulher, atravessam o tempo e a história nas práticas discursivas. O que atualmente é entendido e aceito por "ser masculino" contém algumas particularidades se comparadas com o que era entendido há duas décadas ou até menos. Isso se materializa nas mais diversas linguagens ${ }^{5}$, que nada mais são do que refrações das nossas formas de entender o mundo e existir nele. É no corpo que, de imediato, essas marcas de gênero são ensinadas e legitimadas; por isso que é no corpo que as mudanças são logo identificadas e no corpo pretendem ser rapidamente reprimidas e avaliadas quando desviadas da norma. Essas inscrições não são naturais, dado que "o modelo vigente é imposto ao homem desde que ele nasce. A virilidade não é um dado natural, deve ser construída repetidamente" (JANUÁRIO, 2016, p. 93).

O que seriam, então, as masculinidades? Historicamente, a masculinidade esteve vinculada aos padrões patriaciais - e, portanto, coloniais - desajustados e teve como referência o "não ser", ou seja, aquilo que a masculinidade não é, "por categorias de diferenciação como não ser feminino, não ser homossexual, não possuir traços femininos ou andrógenos" (JANUÁRIO, 2016, p. 92). Em outras palavras, a masculinidade se desenhou ao longo da histórica em negação às características entendidas como normais ao gênero feminino, buscando rechaçá-las. Nessa empreitada do não ser feminino, surge a reiterada necessidade de o homem atestar a sua masculinidade nas suas práticas não só para os outros, mas para si também, um processo penoso que vai desde a castração e supressão de sentimentos como a sensibilidade, a fragilidade e o próprio prazer (JANUÁRIO, 2016) para dar espaço à construção, naturalizada, de um sujeito bruto, valente e desinteressado sentimentalmente.

Raewyn Connell (2005), uma das maiores expoentes nos estudos da masculinidade, desenvolveu uma teoria social a respeito da existência de múltiplas masculinidades, as quais estão alicerçadas nas relações de poder, social e historicamente construídas. Nesse sentido, Connell (2005) e Januário (2016) entendem que

é preciso pensar a masculinidade não apenas como uma característica da identidade pessoal, mas como algo que se encontra presente nas relações sociais, nas instituições e no mercado de trabalho (JANUÁRIO, 2016, p. 112).

${ }^{5}$ Verbal, corporal, visual, etc. 
V. $11(3)$ $255-276$ set-dez 2021

Dessa forma, "não existe, por isso, um modelo único de masculinidade permanente que se aplique a qualquer grupo social ou a qualquer período da história" (JANUÁRIO, 2016, p. 111), pois ele é fluido como o tempo, as exigências e as preocupações sociais. Nesse entendimento, Judith Butler (2019) também indica que não é possível entender com rigidez tanto a masculinidade quanto a feminilidade. Sendo assim, as masculinidades são construções histórico-sociais e culturais, isto é, práticas que se desenvolvem em um processo que é individual e social concomitantemente, que necessita ser desnaturalizado para que as masculinidades outras sejam entendidas como igualmente legítimas.

Diante disso, Connell (2005) conceitualiza a existência de quatro padrões principais de masculinidade. Ressaltamos que eles se pautam na ordem de gênero no ocidente ${ }^{6}$, a saber: a hegemônica, a cúmplice, a subordinada e a marginalizada. Antes de discorrer a respeito do primeiro tipo de masculinidade elencado, esclarecemos que o conceito de hegemonia está sendo entendido como um conceito mutável no âmbito da masculinidade, que varia de acordo com as configurações sociais. Portanto, a masculinidade hegemônica referese "à estrutura que sustenta o poder e àquilo que muitos homens são levados a apoiar" (JANUÁRIO, 2016, p. 124), que tem como referência o patriarcado, os efeitos da colonialidade do poder e, como garantias, as posições de dominação sobre a mulher e as outras masculinidades. Entre as características fulcrais desse tipo de masculinidade está a heterossexualidade. Nessa lógica, o padrão desse tipo de masculinidade seria "o homem branco, ocidental, financeiramente estável e heterossexual" (JANUÁRIO, 2016, p. 121).

Segundo Januário (2016, p. 125), desenvolvendo as ideias de Connell (2005), a masculinidade cúmplice consiste nos homens que se reconhecem nas práticas da masculinidade hegemônica, apesar de não se encaixarem integralmente no padrão dessa masculinidade. Embora não admitam abertamente dita posição, usufruem dos benefícios desse sistema hegemônico. A masculinidade subordinada foi utilizada por Connell (2005) para tratar especificamente das relações hierárquicas existentes entre os grupos de homens, isto é, a dominação heteronormativa, principalmente sobre os homossexuais, mas não apenas sobre eles, senão a todos aqueles que podem ser excluídos do círculo de legimitidade. Por fim, na masculinidade marginalizada estão todos os homens que não se encaixam na masculinidade hegemônica,

${ }^{6}$ Patriarcal, eurocêntrico e capitalista (SANTOS, 2018). 
que são tolhidos socialmente de compartilhar muitas das características dessa masculinidade devido à sua condição de classe social ou etnia marginais (JANUÁRIO, 2016).

Considerando esse preâmbulo teórico que alude às questões centrais deste estudo, a saber, a colonialidade do poder, a abjeção e as masculinidades, a seguir apresentamos os parâmetros metodológicos de uma pesquisa realizada em um aplicativo voltado para a sociabilidade homoerótica: o Grindr.

\section{Orientações metodológicas}

A partir de uma pesquisa qualitativo-interpretativista, tendo como ancoragem teórico-metodológica os estudos do Círculo de Bakhtin, buscamos problematizar questões inerentes à construção da masculinidade homoerótica no Grindr, aplicativo voltado para a sociabilidade homoafetiva. Convém ressaltar que não dispensamos a quantificação de alguns dados, em virtude da sua necessidade para a observação da reincidência dos fenômenos discursivos examinados para o desenvolvimento das nossas interpretações.

O objetivo deste estudo se constituiu em analisar como foi apresentada essa masculinidade por meio da identificação de práticas discursivas de colonialidade nas linguagens e discursos presentes no aplicativo. Ressaltamos que se trata de uma análise aberta ${ }^{7}$ (ROHLING, 2014) em que os resultados desta pesquisa não podem ser generalizados a todos os contextos em que o aplicativo é operado, em razão de que "melhor entendemos a completude - não a totalidade - das relações humanas quando escutamos as vozes locais para tratar de problemas locais" (MOREIRA JÚNIOR, 2018, p. 65).

O Grindr existe desde 2009 e "se tornou o maior aplicativo de rede social para gays, bi, trans e queer", segundo informações do site oficial do aplicativo. Esse programa disponibiliza aos seus usuários, que o utilizam na versão gratuita, aproximadamente 110 perfis para interação, considerando a geolocalização imediata dos conectados. Para esta pesquisa, acessamos o aplicativo nessa versão sem custos e fizemos a captura de tela de 167 perfis do aplicativo. Esses dados foram gerados durante os meses de agosto e setembro de 2019, geolocalizados em uma região periférica da cidade de Maceió, em Alagoas. Para as interpretações,

7 "[...] em que as regularidades dos dados direcionam o diálogo. No entanto, o contorno/ acabamento realiza-se ancorado no objetivo da pesquisa" (ROHLING, 2014, p. 58). 
V. 11 (3)

$255-276$

set-dez

2021

analisamos (a) as informações relacionadas ao layout do aplicativo, (b) as categorias ${ }^{8}$ para criação do perfil de usuário e (c) as respostas a essas categorias, isto é, as performatividades9 (BUTLER, 2019) dos usuários. Consideramos como performatividades os padrões comportamentais desses usuários, as quais são entendidas como (re)produções reiteradas de uma norma social. Entre as categorias presentes no aplicativo, exploramos seis delas para análise: foto do perfil, nome de exibição, sobre mim, sexo, minhas tribos e saúde sexual ${ }^{10}$. Esclarecemos que não constituiu o corpus deste estudo nenhum tipo de interação direta ou indireta entre os pesquisadores e os usuários dos 167 perfis analisados.

O percurso analítico se deu a partir dos procedimentos a seguir, considerando a proposta de Rohling (2014), orientada pelos estudos do Círculo de Bakhtin para uma Análise Dialógica do Discurso: (a) O estudo da esfera de atividade humana, em que se dão as interações discursivas, a saber, a esfera digital, mais especificamente, um aplicativo voltado para a sociabilidade homoafetiva; (b) A descrição dos papéis assumidos pelos sujeitos das interações discursivas, a saber, usuários do aplicativo; (c) O estudo do cronotopo dos enunciados, sendo o próprio aplicativo o cronotopo das interações discursivas materializadas na comunicação desses usuários; (d) O estudo do horizonte temático valorativo dos enunciados que circulam no aplicativo; e (e) A análise das relações dialógicas, isto é, as posições valorativas dos sujeitos nas interações no aplicativo.

Na seção seguinte, apresentamos as análises das práticas discursivas no tocante à masculinidade homoerótica no aplicativo em jogo. Tratam-se de práticas discursivas que, tanto a disposição imagética e organizacional do aplicativo quanto as interações dos usuários, indicam degradar a masculinidade homossexual. Em outras palavras, elas apontam para uma patologização da construção identitária homoerótica à luz da masculinidade hegemônica.

\footnotetext{
${ }^{8}$ Entendemos por "categorias" os itens que os usuários preenchem para a criação do seu perfil no aplicativo (nome, idade, altura, peso...).

9 "A performatividade deve ser compreendida não como um 'ato' singular e deliberado, mas, em vez disso, como prática reiterativa e citacional pela qual o discurso produz os efeitos que nomeia" (BUTLER, 2019, p. 195).
}

${ }^{10}$ Assim são nomeadas originalmente no Grindr. 


\section{Os discursos patologizantes sobre a masculinidade homoerótica}

A partir da interpretação dos dados coletados para esta pesquisa, verificamos como a regularidade de discursos patologizantes a respeito das construções identitárias homoeróticas, mais especificamente relacionadas à masculinidade, ancorados tanto nas linguagens que constituem o layout do aplicativo voltado para a sociabilidade homoafetiva, o Grindr, quanto num amplo recorte de enunciados interativos dos usuários nos seus perfis, circunscreve o homem gay em um não-espaço. Nessa perspectiva, identificamos a patologização da masculinidade homossexual como ponto de análise neste trabalho, a qual entendemos por duas linhas que são desenvolvidas a seguir: a da enfermidade e a do distúrbio social, ambas ultrajantes na construção identitária de um grupo social que historicamente buscou desprenderse dessas concepções, as quais parecem ter sido regadas em um ambiente que deveria favorecer e impulsionar um espaço de liberdade e resistência.

\section{Enfermidade}

A patologização como enfermidade pode ser indicada na disposição de duas categorias que são propostas aos usuários do aplicativo, cujas respostas a essas categorias são compartilhadas no próprio programa aos que com eles interagem, a saber, "saúde sexual" e "minhas tribos".

O aplicativo propõe aos seus usuários que compartilhem informações sobre a sua saúde sexual. Entre todas as doenças sexualmente transmissíveis, o aplicativo se limita à síndrome da Imunodeficiência Adquirida, a Aids, por meio da possível partilha de informações sobre a realização do exame de detecção do vírus da imunodeficiência humana dos usuários, o HIV, de maneira que também é concedido compartilhar a data (mês e ano) do último teste realizado e a possibilidade de ativar, no próprio aplicativo, um lembrete para a realização do teste ${ }^{11}$. Lembremos que a sorologia positiva para o HIV não corresponde à doença, a Aids, causada por esse vírus. O HIV se trata de uma infecção sexualmente transmissível (IST) que não tem necessariamente sinais ou sintomas, o que não impede a sua transmissão. O fato é que as outras IST foram "esquecidas" no aplicativo, como sífilis e gonorreia, cujos casos têm aumentado muito nos

\footnotetext{
${ }^{11}$ As opções proporcionadas pelo aplicativo são: "depois de 3 meses" e "depois de 6 meses".
} 
V. 11 (3)

$255-276$

set-dez

2021

últimos anos por conta da profilaxia pré-exposição ao HIV (PrEP), que só impede o alastramento da infecção do HIV. Nas últimas atualizações da plataforma, o Grindr também possibilita que os seus usuários informem, nessa mesma categoria, "saúde sexual", o uso de PrEP.

A problematização se pauta na tentativa de entender a necessidade do compartilhamento desse tipo de informação, a soropositividade, que, sociohistoricamente, é sensível, estigmatizada, permeada de tabus e, por isso, ainda constrangedora. Sobretudo porque essa informação se faz presente em um aplicativo voltado para a sociabilidade entre homens não heterossexuais, uma vez que a partilha dessa informação inexiste em outros aplicativos para esse tipo de interação. Para entendermos o estranhamento da existência dessa categoria nesse tipo de tecnologia que busca a aproximação de pessoas, é necessário entender as implicações dos discursos colonialistas e, portanto, hegemônicos, que estão em órbita e os seus efeitos na perpetuação de discursos dessa ordem no imaginário social a respeito dos homens homoeróticos. Como esclarece Volóchinov (2018, p. 194), "as formas de enunciado inteiro podem ser sentidas e compreendidas apenas em comparação com outros enunciados inteiros na unidade de uma esfera ideológica".

A Aids, desde o início da década de 1980, antes mesmo dos primeiros estudos científicos a respeito da doença, cultural e sociohistoricamente, ela foi e continua sendo relacionada a uma doença de homens gays. Este discurso recaiu sobre esse grupo social e viajou o tempo, resistindo-se. Essa associação deriva da correspondência que havia entre os primeiros enfermos e a então nova doença. A Aids já era classificada socialmente como "câncer gay", "pneumonia gay" e até "peste gay" (TIMERMAN; MAGALHÃES, 2015). Na Academia, a doença chegou a receber a sigla DIRG, que significava "Doença Imunológica Relacionada aos Gays". Os resultados das primeiras análises confirmaram a suposição de que aquela doença estava relacionada ao comportamento sexual. Anos seguintes, após o mapeamento das principais formas de transmissão do HIV, a doença foi renomeada. Passou a ser chamada de "Doença dos 5H", fazendo referência aos homossexuais, hemofílicos, haitianos, heroinômanos e hookers ${ }^{12}$, nos quais o vírus aparecera substancialmente.

12 "Gíria, em inglês, que designa as profissionais do sexo" (TIMERMAN; MAGALHÃES, 2015, p. 91). É curioso perceber que o primeiro "H" é marcado pelos homossexuais, respondendo a uma compreensão social de que este seria o grupo mais reincidente. 
Desde estão, os discursos resultantes dessa associação atravessaram o tempo e ainda precipitam nos corpos dos homens homoeróticos na perpetuação de um mantra: a Aids é coisa de gays, pois "o fato de a doença ter sido descoberta no universo gay fez recair um enorme estigma sobre os homossexuais" (TIMERMAN; MAGALHÃES, 2015, p. 91), o que implicou, inclusive, na incorporação deles no grupo de risco, ou seja, o grupo que contrai e transmite a doença, intensificando a abjeção, pela suposta população hegemonicamente heterossexual, invulnerável à doença por sua orientação sexual, contra os homoeróticos homens, principalmente.

Ao identificarmos as respostas dos perfis pesquisados à categoria "saúde sexual", nenhum usuário entre os 167 sinalizou ter o resultado positivo para o exame de HIV. Entre esses perfis, 118 não compartilharam nenhuma informação a respeito dessa categoria; 16 indicaram resultado negativo, sem data do último exame, e 33 sinalizaram negativo, com data do último exame. Esses dados nos levam à leitura de que não seria interessante aos usuários a divulgação ou nem mesmo a menção desse tipo de informação em decorrência da névoa de tabus e, consequentemente, as rejeições ou entraves que o fornecimento dessa informação poderia provocar na interação entre eles. Em 2018, segundo o periódico $\mathrm{G}^{13}$, o Grindr compartilhou o status de HIV dos usuários com outras empresas, talvez o dado mais sensível presente no aplicativo, além de outras informações dos usuários as quais a este dado estavam vinculadas, eventualmente para fins comerciais. À nossa leitura, isso demonstra o quão esse dado é delicado socialmente. Diante disso, o aplicativo recupera e ratifica uma imagem social de que existem duas classes de homoeróticos, os soronegativos e os soropositivos ${ }^{14}$, validando a ideia de que os homossexuais é um grupo de risco, patológico, por conta da sua orientação sexual.

Além dessa oportunidade que a plataforma Grindr escancara aos seus usuários para a revelação de uma provável infecção pelo vírus HIV, a categoria "minhas tribos" também aviva, como mais uma alternativa, uma nova possibilidade de o usuário revelar-se soropositivo, agora como integrante de uma comunidade singular.

\footnotetext{
${ }^{13}$ Fonte: BBC. App de relacionamento gay Grindr compartilhou status de HIV de usuários com outras empresas. G1, 2018. Disponível em: https://g1.globo.com/economia/tecnologia/noticia/ app-de-relacionamento-gay-grindr-compartilhou-status-de-hiv-de-usuarios-com-outrasempresas.ghtml. Acesso em: 06 nov. 2020.

${ }_{14}$ Reforçamos que ser soropositivo para o HIV não significa que a pessoa é aidética, principalmente nos dias atuais.
} 
V. 11 (3) 255-276 set-dez 2021
Sob essa perspectiva, entendemos, portanto, que a soropositividade possui uma carga patologizante com relação ao paradigma de pessoa "normal", que possivelmente seria abjeta no aplicativo. O efeito é tão naturalizador que põe no mesmo plano a condição de "soropositivo" com outras tribos como "discreto", "cafuçu", "malhadinho", "trans", "garotos", entre outras, atribuindo-lhe um entendimento familiar e consolidado de que homens homoeróticos, compreensivelmente, podem ser plausíveis portadores do HIV.

Por meio desse entendimento, explicamos a inexistência de usuários que se autodeclarassem integrantes da tribo "soropositivo" entre os 167 perfis analisados. Aos portadores do vírus, tornar-se-ia muito delicado compartilhar esse tipo de informação nessa categoria, pois "o abjeto é algo pelo que alguém sente horror ou repulsa como se fosse poluidor ou impuro, a ponto de ser o contato com isso temido como contaminador e nauseante" (MISKOLCI, 2017, p. 44), o que possivelmente inibiria qualquer tentativa de sociabilidade proposta pelo aplicativo. Isso nos ajuda a entender de onde desponta a violência por meio de xingamentos, injúrias e outros ataques verbalizados, como discutimos na subseção seguinte.

Distúrbio social

Outra linha de análise identificada é a patologização como distúrbio social. Com isso, queremos evidenciar a reincidência do lugar do homoerótico em um espaço de invisibilidade, o que nomeamos neste texto de não-espaço, isto é, a condição social em que a masculinidade hegemônica se sobrepõe e é referência para o ser homem, e todos os aspectos desviantes dessa norma são coarctados, reprimidos e até vilipendiados explicitamente ou não. Esses aspectos servem "para estigmatizar e marginalizar performances de gênero desviantes enquanto, ao mesmo tempo, reforça[m] padrões normativos de masculinidade e feminilidade" (PARKER, 2002, p. 57 apud DARDE 2008, p. 227-228).

A ideia de dissimulação da homossexualidade, como discrição, na nossa interpretação, já é conduzida pelo próprio ícone do aplicativo, representado por uma máscara em cor alaranjada. Pelas características desse acessório, que tem a função de cobrir a face ou parte dela, entendemos que ele não projeta a ideia lúdica ou até mesmo sexual para fazer alusão a um fetiche libidinoso; pelo contrário, alude a uma 
ideia de proteção da face completa de uma possível identificação, uma vez que essa máscara não possui características eróticas, o que alimenta a ideia de sigilo e discrição de qualquer exposição desse tipo de masculinidade. Ao considerarmos a masculinidade enquanto um traço da matriz de inteligibilidade de homens gays, entendemos que o sigilo e discrição contribuem para esse "esconderijo". Contudo, não podemos nos esquecer de que o usuário tem a possibilidade de não colocar nenhuma informação em seu perfil, nem mesmo deixar visível a distância que se encontra em relação aos outros conectados. Essas estratégias invisibilizam o usuário de forma que é possível não ser visto, mas, ao mesmo tempo, continuar vendo/lendo/ouvindo as interações que acontecem naquele espaço e permanecer em silêncio, daí que os únicos orifícios da referida máscara sejam justamente os dos olhos.

Alinhado a esse aspecto do layout do aplicativo, constatamos que a maior parte dos usuários do Grindr não põe a foto de seus rostos nos seus respectivos perfis. De um total de 167 perfis analisados, apenas 35 deles se identificaram com uma foto do rosto ${ }^{15}$ completo, os outros usuários preferiram a foto do corpo ou de partes dele, ou optaram por imagens aleatórias, ou por imagem nenhuma. Além disso, na categoria "nome de exibição", onde se espera que haja o nome do usuário, apenas 27 usuários revelaram os seus supostos nomes, apelidos e/ou sobrenomes.

Entendemos que esse recuo no compartilhamento da foto de rosto e do nome do usuário no perfil do aplicativo é um efeito da colonialidade na masculinidade homoerótica, a qual se vê socialmente coibida, inclusive em um aplicativo onde supostamente todos são não heterossexuais, a se sentirem em um não-espaço. A identificação desse traço identitário, a masculinidade gay, ainda é motivo de escárnio e constrangimento sociais se ele atravessa as fronteiras do armário social, por isso deve ser preservado, inclusive no espaço que deveria fomentar o reconhecimento.

A experiência da abjeção deriva do julgamento negativo sobre o desejo homoerótico, mas sobretudo quando ele leva ao rompimento de padrões normativos como a demanda social de gays e lésbicas sejam "discretos", leia-se, não pareçam ser [e não se identifiquem como] gays ou lésbicas (MISKOLCI, 2017, p. 45).

${ }^{15}$ Devemos considerar também a possibilidade de que a foto de rosto publicada não corresponda à real identidade do usuário. 
V. 11 (3) 255-276 set-dez 2021
Figura 1 - Transcrição do texto da categoria

"sobre mim" de um usuário do aplicativo

Oi+foto do rosto.

bora pro lolzinho?

pq vcs faz tanto romance para mandar uma foto? meu Deus que agonia

Fonte: Acervo dos autores.

Portanto, a discrição - ou melhor, a tentativa de apagamento de traços não heteronormativos - tornou-se uma convenção nas interações realizadas no aplicativo, isto é, normalizou-se a ideia de que apenas na conversa privada é que o usuário apresenta o seu rosto ao outro usuário com quem deseja interagir, como se constata, na figura 1, o pedido desse usuário para, após o primeiro cumprimento, enviar uma foto de rosto. No entanto, essa apresentação da face também tem seus impasses, pois se espera que o outro ceda primeiramente a foto para, então, o seu interlocutor compartilhar a sua também, sendo, além de uma convenção, um entrave para a interação, como questiona o mesmo usuário: "pq vcs faz (sic) tanto romance pra mandar uma foto? meu Deus que agonia". Esse encunciado ratifica a dificuldade que os usuários têm de partilhar a foto de seus rostos, mesmo em conversas privadas, perante o medo de serem identificados inesperadamente como homoeróticos que compartilham o mesmo espaço social do seu interlocutor, isto é, como homoerótico-parente, homoerótico-amigo, homoerótico-professor, homoerótico-aluno, homoerótico-político, homoerótico-vizinho, homoerótico-colega-de-trabalho, etc.

Figura 2 - Transcrição do texto da categoria

"sobre mim" de um usuário do aplicativo

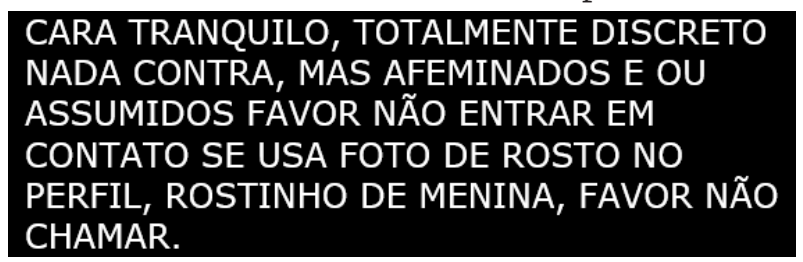

Fonte: Acervo dos autores.

Entendemos esse resguardo como um recurso de segurança na possibilidade de o usuário ser reconhecido por pessoas que comprometeriam socialmente a sua imagem ao ser identificado como homoerótico estigmatizado. Assim, o usuário tem a possibilidade de se proteger dessa exposição ao não retribuir a foto quando o outro se 
identifica ou até mesmo bloqueá-lo na interação. Portanto, estar nesse espaço homoerótico torna-se um lugar impróprio, de controle, um nãoespaço que se norteia na não (auto)identificação como um homossexual. Isso se reforça na figura 2, uma vez que a exposição da foto de rosto no perfil, independentemente de o usuário ter ou não traços da masculinidade hegemônica, pode romper a possibilidade de uma interação.

Existe, portanto, uma tentativa patológica de não ser identificado como homoerótico, em um espaço não heterossexual, como também de não encontrar no outro características desviantes da heteronormatividade para uma possível interação e/ou relação, seja ela de que ordem for. Assim, ser homem homossexual, como modelo aceitável para interação no aplicativo, é entendido como ser macho, discreto, sigiloso, rude e não afeminado. Todas essas características descendem do protótipo de homem heterossexual moderno que parece ser cultuado e estar cristalizado como padrão de masculinidade.

Figura 3 - Transcrição do texto da categoria "sobre mim" de um usuário do aplicativo

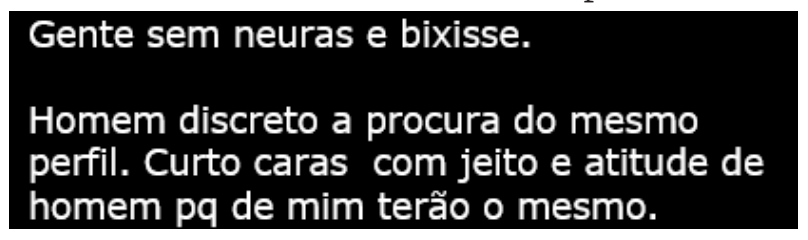

A recorrente autoidentificação como "macho" nos perfis analisados, já na categoria "nome de exibição", evoca a masculinidade hegemônica e os discursos que essa masculinidade lhe confere, isto é, um homem sem características ou posturas femininas ("rostinho de menina", cf. figura 2), tampouco com performatividades que vão de encontro à masculinidade viril ("gente sem neuras e bixisse", cf. figura 3). Esses discursos passam, inclusive, por um processo de polidez quando os usuários negam com anterioridade a existência de um desejo por homens com traços categorizados socialmente como femininos.

Figura 4 - Transcrição do texto da categoria

"sobre mim" de um usuário do aplicativo

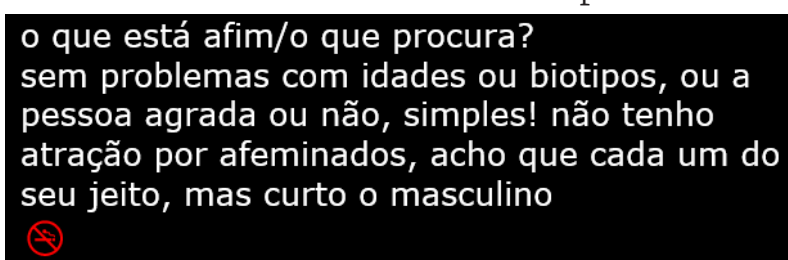

Fonte: Acervo dos autores. 
V. 11 (3)

255-276

set-dez

2021
Figura 5 - Transcrição do texto da categoria

"sobre mim" de um usuário do aplicativo

Tenho local, afim apenas de curtir e nada de

mais, não tô afim de relacionamentos. curtição de

boas e no sigilo. curto tudo Não curto

afeminados não insista, nada contra, apenas

não curto.

Fonte: Acervo dos autores.

Figura 6 - Transcrição do texto da categoria

"sobre mim" de um usuário do aplicativo

\section{as afeminadas corram q odeio}

Fonte: Acervo dos autores.

Essa polidez é notória em discursos como "acho que cada um [é] do seu jeito" (cf. figura 4) ou "nada contra" (cf. figura 5), que são posteriormente desempoeirados quando, nas respectivas figuras, os usuários registram "mas curto o [jeito] masculino", que corresponde à masculinidade hegemônica, e "não insista, nada contra, apenas não curto", como uma indicação clara de abjeção a qualquer forma de contato com pessoas que tenham algum grau de feminilidade. A abjeção chega ao estágio de ódio e repugnância, como exemplifica o discurso da figura 6. Essa construção naturalizada do ser homem como um arquétipo de virilidade é projetada e supostamente esperada pelo outro ao ponto de o usuário da figura 3 reiterar essa masculinidade como um lugar de pertencimento e perpetuação "pq de mim terão o mesmo". A respeito disso, Louro explica que

os discursos e as práticas que constituem o processo de masculinização implicam a negação de práticas ou características referidas ao gênero feminino e essa negação se expressa, muitas vezes, por uma intensa rejeição ou repulsa dessas práticas e marcas femininas (o que caracterizaria, no limite, a misoginia) (LOURO, 2011, p. 67).

Figura 7 - Transcrição do texto da categoria

"sobre mim" de um usuário do aplicativo

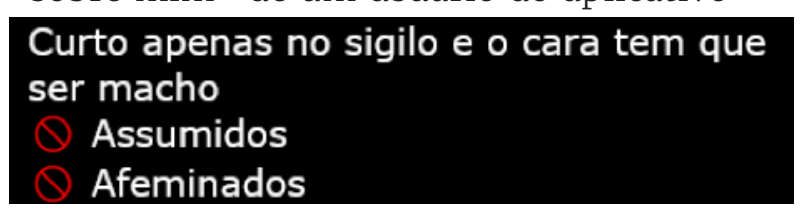

Fonte: Acervo dos autores.

Essa abjeção se aplica não apenas àqueles que são identificados como afeminados como também àqueles que se identificam social e abertamente como homoeróticos, isto é, como gays assumidos (cf. figura 7). Esse cultivo patologizante da masculinidade hegemônica 
ressignificou, inclusive, a categoria "sobre mim" do aplicativo, que certamente foi pensada para que os usuários discorressem brevemente sobre eles próprios. No entanto, como exemplificam os dados analisados, não há dúvidas de que esse espaço se tornou um balcão de exigências sobre o que se espera do outro, uma espécie de prescrição rigorosa de homem, que dilacera a possibilidade de contato com quem não se adequa a ela.

\section{Considerações finais}

As interpretações apresentadas evidenciam uma masculinidade homoerótica patologizada e (re)produzida, sob a égide de uma masculinidade hegemônica (CONNELL, 2005), a partir de discursos coloniais socializados em um regime de terrorismo cultural (MISKOLCI, 2017), isto é, discursos coletivamente impostos e experienciados no aplicativo. Essa patologização foi percebida de duas formas: pelo viés da enfermidade e pelo viés do distúrbio social.

Na linha da enfermidade, ficou clara na nossa interpretação a associação feita entre a infecção e transmissão do HIV e o público daquele aplicativo, homens homoeróticos, por meio do incentivo à partilha da situação viral dos usuários do Grindr, uma característica particular desse aplicativo. Pelo viés do distúrbio social, percebemos as reiteradas tentativas de promoção de uma masculinidade hegemônica e obliteração de possíveis interações com usuários que não compartilham dessa masculinidade idealizada, o que implicou em convenções específicas para essas interações, são elas: o ocultamento do rosto e do nome do usuário no perfil e a presença de critérios de homem másculo para a interação na categoria "sobre mim". Chega-se, dessa forma, a duas classificações binárias, coloniais e, portanto, patologizantes acerca da masculinidade homoerótica naquele espaço virtual: os portadores do vírus HIV versus os não portadores do vírus HIV e os homens versus as bichas, que não deixam de ser reverberações de discursos amplamente consolidados nos mais diversos espaços sociais sobre essa masculinidade.

Nesse sentido, as práticas discursivas analisadas apontam para um desconforto da masculinidade homoerótica em um espaço destinado para o contato daqueles que cotidianamente vivem em um não-espaço para interações amorosas. Esse não-espaço, um aplicativo voltado para a sociabilidade homoafetiva, chega, paradoxalmente, a possuir características de homofobia, uma vez que esse termo 
V. 11 (3)

$255-276$

set-dez

2021 designa, assim, dois aspectos diferentes da mesma realidade: a dimensão pessoal, de natureza afetiva, que se manifesta pela rejeição dos homossexuais; e a dimensão cultural, de natureza cognitiva, em que o objeto da rejeição não é o homossexual enquanto indivíduo, mas a homossexualidade como fenômeno psicológico e social (BORRILLO, 2015, p. 22).

Torna-se preocupante esse tipo de discurso em um ambiente digital, visto que a plataforma poderia ser um espaço seguro e respeitoso para a interação entre aqueles que compartilham de características afetivas semelhantes, pois "ironias, piadas, injúrias e ameaças costumam preceder tapas, socos ou surras" (MISKOLCI, 2017, p. 35) que não só atacam corpos, mas também constroem um imaginário social de verdades absolutas que desumanizam e patologizam a masculinidade homoerótica, como se pôde acompanhar nas análises. Assim, entendemos essas verdades como contingentes, "uma construção que, por ser muito partilhada, parece uma representação, mas é apenas porque é partilhada" (SANTOS, 2018, p. 33). Para esse entendimento, foi imprescindível historicizar os discursos orbitantes acerca da construção da masculinidade homoerótica para, então, compreender o quanto as práticas discursivas, como as aqui analisadas, precipitam perversamente sobre os homossexuais. Como esclarece Bakhtin (2011, p. 300), "o falante não é um Adão", ele sempre responde a enunciados que o antecederam, não podendo se desprender deles, sejam esses enunciados conscientes ou não, dado que cada ato social e, portanto, discursivo "de modo algum pode ser reconhecido como um fenômeno individual no sentido exato dessa palavra" (VOLÓCHINOV, 2018, p. 200).

É impraticável, pois, não conceber os enunciados analisados como atos sociais, os quais, neste trabalho, patologizam a masculinidade homoerótica como efeito de uma historicidade coletiva mórbida sobre esse grupo social. Por isso, "a sutileza do embate cultural requer um olhar igualmente sutil" (LOURO, 2008, p. 21) para não legitimar mentiras sobre quem são sujeitos normais, adequados e sadios e quem se diferencia desse perfil. Como declara Hendel (2017), as mentiras do patriarcado são sutis, as quais (re)produzem as desigualdades com o intuito de perdurar uma vida fragilizada para que situações de dominação e subordinação não sejam sentidas como tais.

\section{Referências}

BADINTER, E. XY: sobre a identidade masculina. Tradução: Maria Ignez Duque Estrada. Rio de Janeiro: Nova Fronteira, 1993. 
BAKHTIN, M. Estética da criação verbal. Tradução: Paulo Bezerra. 6. ed. São Paulo: Editora WMF Martins Fontes, 2011.

BALLESTRIN, L. América Latina e o giro decolonial. Revista Brasileira de Ciência Política, Brasília, n. 11, p. 89-117, 2013.

BORRILLO, D. Definições e questões terminológicas. In: BORRILLO, D. Homofobia: história de um preconceito. Tradução: Guilherme João de Freitas Teixeira. Belo Horizonte: Autêntica Editora, 2015, p. 21-41.

BUTLER, J. Corpos que pesam: sobre os limites discursivos do "sexo". In: LOURO, G. L. (org.). O corpo educado: pedagogias da sexualidade. 4. ed. Belo Horizonte: Autêntica Editora, 2019, p. 191-219.

CONNELL, R. Masculinities. California: University of California Press, 2005.

DARDE, V. A construção de sentidos sobre a homossexualidade na mídia brasileira. Em Questão, Porto Alegre, v. 1, n. 2, p. 223-234, jul/dez, 2008.

DUSSEL, E. 1492: El encubrimiento del Otro: hacia el origen del "mito de la Modernidad". La Paz: Plural Editores, 1994.

FABRÍCIO, B. Linguística Aplicada como espaço de "desaprendizagem": redescrições em curso. In: MOITA LOPES, L. P. (org.). Por uma Linguística Aplicada Indisciplinar. São Paulo: Parábola Editorial, 2006, p. 45-65.

GROSFOGUEL, R. Para descolonizar os estudos da economia política e os estudos pós-coloniais: transmodernidade, pensamento de fronteira e colonialidade global. Revista Crítica de Ciências Sociais, n. 80, p. 115-147, 2008.

HENDEL, L. Ciudadanía de baja calidad. In: HENDEL, L. Violencias de género: las mentiras del patriarcado. Ciudad Autónoma de Buenos Aires: Paidós, 2017, p. 37-74.

JANUÁRIO, S. Masculinidade: historicidade, pluralidade e construção. In: JANUÁRIO, S. Masculinidades em (re)construção: gênero, corpo e publicidade. Covilhã: Labcom Books, 2016, p. 80-151.

LOURO, G. Educação e docência: diversidade, gênero e sexualidade. Revista Formação Docente, Belo Horizonte, v. 3, n. 4, p. 62-70, 2011.

LOURO, G. Gênero e sexualidade: pedagogias contemporâneas. Pro-Posições, Unicamp, v. 19, n. 2, p. 17-23, 2008.

MALDONADO-TORRES, N. Sobre la colonialidad del ser: contribuciones al desarrollo de un concepto. In: CASTRO-GÓMEZ, S.; GROSFOGUEL, R. (org.). El giro decolonial: reflexiones para una diversidad epistémica más allá del capitalismo global. Bogotá: Siglo del Hombre Editores, 2007, p. 127-168.

MignolO, W. Desafios decoloniais hoje. Epistemologias do Sul. Foz do Iguaçu/PR, p. 12-32, 2017.

MISKOLCI, R. Teoria Queer: um aprendizado pelas diferenças. Belo Horizonte: Autêntica Editora: UFOP, 2017. (Série Cadernos da Diversidade). 
V. 11 (3)

255-276

set-dez 2021

MOITA LOPES, L. P. Linguística Aplicada como lugar de construir verdades contingentes: sexualidades, ética e política. Revista Gragoatá, Niterói, n. 27, p. 33-50, 2009.

MOITA LOPES, L. P. Uma linguística aplicada mestiça e ideológica: interrogando o campo como linguista aplicado. In: MOITA LOPES, L. P. (org.). Por uma Linguística Aplicada Indisciplinar. São Paulo: Parábola Editorial, 2006, p. $13-44$.

MOREIRA JÚNIOR, R. S. As perspectivas dos outros: uma necessidade na pesquisa em Linguística Aplicada. Revista Leitura, Maceió, v. 1, n. 60, p. 6268, jan./jun. 2018.

MOTA NETO, J. C. Por uma pedagogia decolonial na América Latina: reflexões em torno do pensamento de Paulo Freire e Orlando Fals Borda. Curitiba: CRV, 2016.

QUIJANO, A. Colonialidad del poder, eurocentrismo y América Latina. In: LANDER, E. (org.). La colonialidad del saber: eurocentrismo y ciencias sociales. Perspectivas latinoamericanas. Buenos Aires: CLACSO, 2000.

ROHLING, N. A pesquisa qualitativa e análise dialógica do discurso: caminhos possíveis. Cadernos de Linguagem e Sociedade, v. 15, p. 44-60, 2014.

SANTOS, B. Na oficina do sociólogo artesão: aulas 2011-2016. São Paulo: Cortez, 2018.

TIMERMAN, A.; MAGALH̃̃̃ES, N. A história por trás das histórias. In: TIMERMAN, A.; MAGALHÃES, N. Histórias da Aids. Belo Horizonte: Autêntica Editora, 2015, p. 77-143.

VOLÓCHINOV, V. Marxismo e filosofia da linguagem: problemas fundamentais do método sociológico na ciência da linguagem. Tradução: Sheila Grillo e Ekaterina Vólkova Américo. 2. ed. São Paulo: Editora 34, 2018. 